\title{
Construction and Analysis of E-pay Payment Framework Based on Campus E-card
}

\author{
Lingxi Zhu \\ Transportation Institute, Beijing \\ Jiaotong University \\ Beijing, China \\ zhulingxi@139.com
}

\author{
Jia Zhu \\ Transportation Institute, Beijing \\ Jiaotong University \\ Beijing, China
}

\author{
Yuan Ling \\ Transportation Institute, Beijing \\ Jiaotong University \\ Beijing, China \\ 06254007@bjtu.edu.cn
}

\begin{abstract}
Combined with the actual situation of the campus network, analyze the structure and application framework of existing E-card system. Combined with the payment system of $\mathbf{E}$ card, a viable framework for e-pay payment is proposed. The proposing of E-pay payment provides solutions for the online application of campus E-card. We also provide different solutions for the flow of recharge, transfer and settle accounts based on the E-pay Payment Framework.
\end{abstract}

Keywords-E-pay (electronic pay); Campus Network; E-card (electronic card); Electronic payment

\section{INTRODUCTION}

The current research on Electronic payment, mainly focus on the business payment activity conducted over the Internet. The research on the electronic payment in the campus network environment lacks the discovery and summary of its characteristics, so as the deeply analysis of payment mode. Secondly, the research on the campus network payment always have no specific, practical payment model to develop effective strategies and mechanisms ${ }^{[1]}$, most of them are generalized. Finally, with the popularity of campus E-card, a growing body of research focused on how to build a campus E-card network, how to achieve their diverse functions, but lack of research on the E-card in payment field, focusing on the technology but neglecting the combination of business process. A lot of schools have invested huge cost in development but the E-card can not really use ${ }^{[2]}$. And research on the E-card is limited to the payment based on the card and machine, NOT based on online payment options of B/S (Browser/Server) ${ }^{[3]}$, this kindly reduce the areas of online payment.

Therefore a combination with the actual situation in the campus network is required, we need to prose the feasible payment plan and framework.

\section{E-PAY PAYMENT PROPOSED}

The E-card based on the campus itself is not available for online payment. In order to provide a feasible solution for the online application of the E-card, we propose to build the framework of E-pay payment. Based on the E-pay account, users can make selection of a payment mechanism to complete the online payment.

The relevant concepts defined in the E-pay payment are as follows:

E-card Number: the only serial number to logo a unique Ecard. Usually it is the student number of the cardholder.

E-card Account: Each E-card corresponds to a unique Ecard account. The accounts are managed by the School Card Center.

"E-pay" account: that is, the personal accounts for the user to do online payment. The account is set up and managed by the School's independent online payment intermediaries. In order to realize the account correspond to the only user, the implementation of binding E-pay account with the E-card number is necessary. The amount of the account only exists in the online payment database, does not exist in the card medium. E-pay account set up two keys, one for the $\log$ of Epay account, can query and submit the request for the payment. The other is payment key. To make payments must enter this key.

Online payment subjects: namely, in the online payment activities, established the different items to facilitate the classification of accounts. Such as submit the Net fee, buy books and other subjects.

E-pay Settlement Account: funds between the E-pay account and the E-card account need the settlement between different agents. In order to complete the settlement between the E-pay account and the E-card account, the E-pay center need to set up the E-card settlement account.

E-card Settlement Account: Just like the E-pay settlement account, in order to complete the settlement between the E-pay account and the E-card account, the E-card center need to set up an E-card settlement account.

\section{RECHARGE HANDLING}

\section{A. Direct Recharge}

E-card as a carrier to funds in two ways to enter the E-pay account, the first is direct recharge, after the establishment of 
the card reader and the validation of the cardholder. To use the cash to recharge the E-pay, E-Card is only a tool at the moment. The flow of recharging the E-pay is shown in Figure 1.

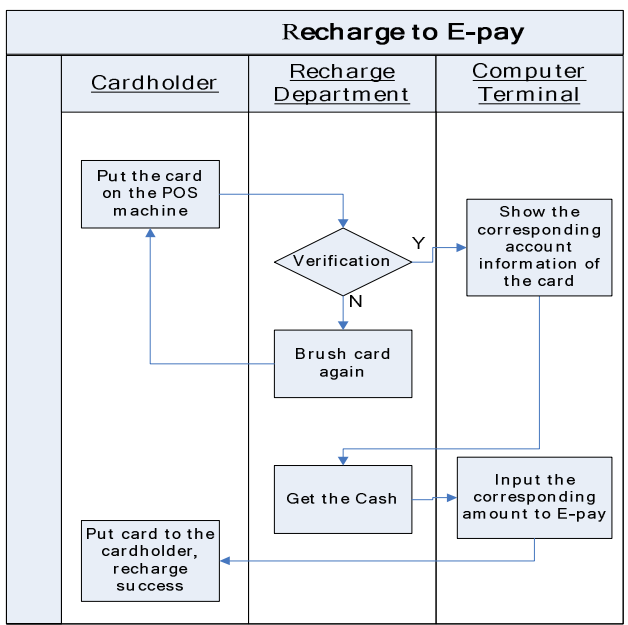

Figure 1. The flow of recharging to E-pay

After the cardholder recharge the E-pay, then put the card on the POS machine. The system will automatically test the legality of E-card, if the E-card can be normal use, computer terminal will show the corresponding information of E-pay account and the cardholder. The Cashier receive the recharge cash and enter the amount to the E-pay account, click "OK" and recharge success.

\section{B. Indirect Recharge}

Another is indirect recharge, that is, a fund is from the cardholder's E-card account to the E-pay account, the flow as shown in Figure 2.

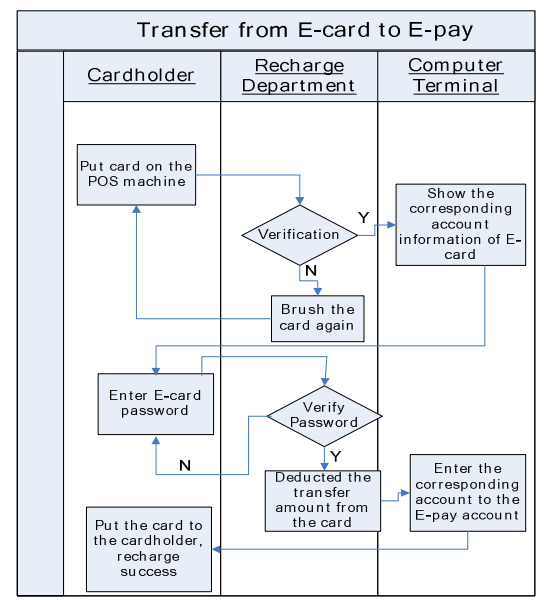

Figure 2. The flow of transferring from E-card to E-pay

After the cardholder recharge the E-pay, then put the card on the POS machine. The system will automatically test the legality of E-card, the cardholder enters the account password and the system verifies the validity of the password. The cashier deducts the amount of transfer funds and shows the amount on computer terminals. Then return the card and transfer success.

\section{SETTLEMENT HANDLING}

The settlement flow from E-card to E-pay is shown in Figure 3.

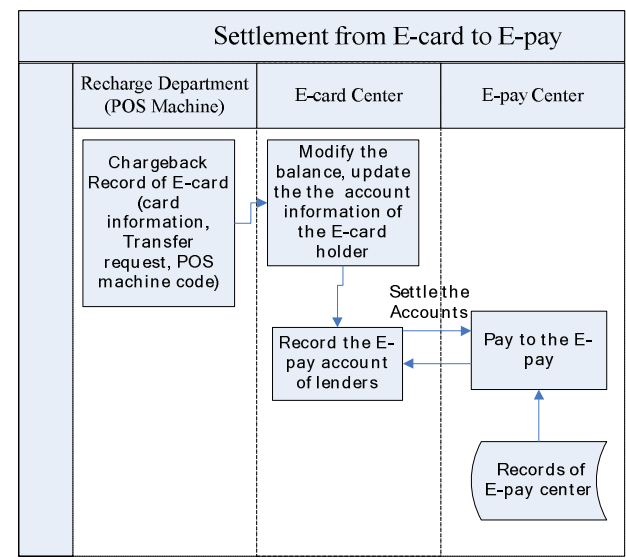

Figure 3. The settlement flow from E-card to E-pay

If the POS machine is online status at the time, the Chargeback record will be sent to the E-Card Center in realtime, notice the system automatically updates the database of E-card account information and modify the balance. At that time, if the POS machine in offline operation, then the POS machine will save the chargeback record and upload after a few second when the POS machine is in the status of online. E-card center will record the E-pay account to the lenders. Handle the settlement with the E-pay Center until the end of a day or a month and transfer the actual amount to E-pay. In the process of settlement, the records in the E-pay Center and E-card Center are both the certification of payment.

\section{WITHDRAWINGING OF ACCOUNT FUNDS}

The withdrawing of online payment account funds can also be used through the E-card in two ways. The first is the way to get the cash. This mode corresponds to the first recharge mode. Getting cash flow from the E-pay is shown in Figure 4. 


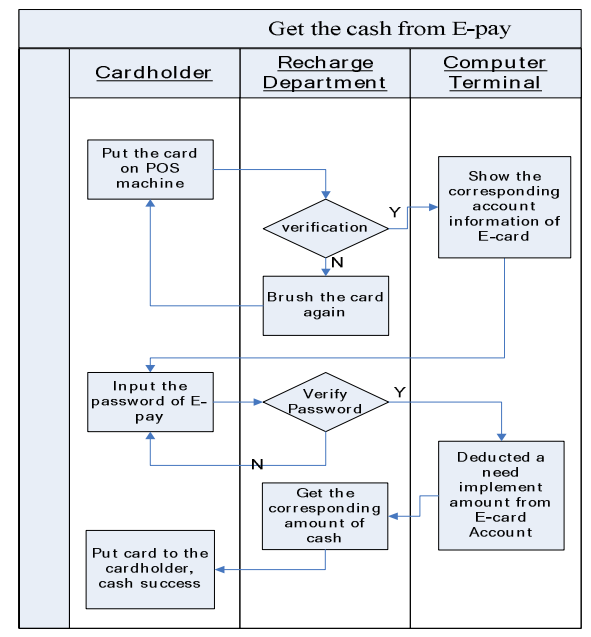

Figure 4. Getting cash flow of the E-pay

The cardholder enters the payment password, after the system test the legality of password, the cashier deduct the amount of withdrawing in the E-pay account. Then return the cash and E-card to the cardholder. So getting the cash from the E-pay is successful.

\section{TRANSFER HANDLING}

The second way of withdrawing the online payment account funds is to transfer to the E-card account. This paper presents two alternative options. Their settlement flows are the same.

\section{A. $\quad$ Program 1}

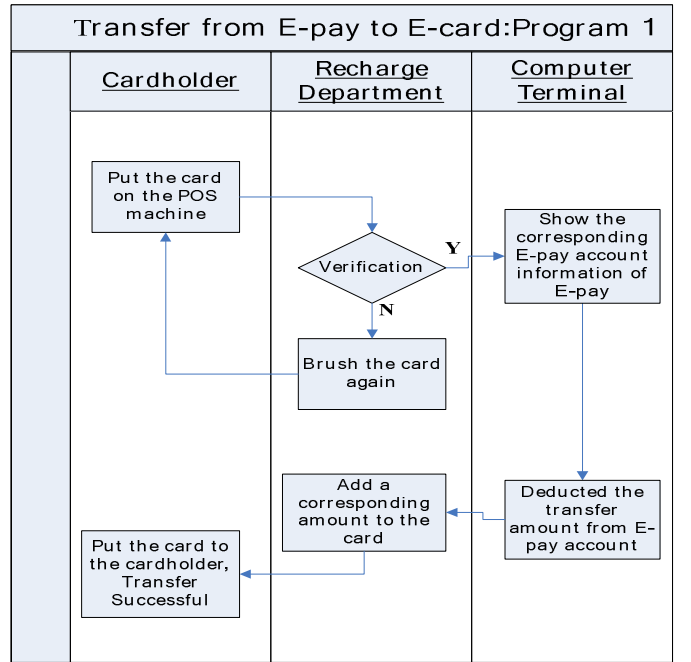

Figure 5. The flow of transferring from E-pay to E-card (Program 1)

The program 1 of transferring from E-pay to E-card is shown in Figure 5. In the E-pay center, the cardholder uses the E-card to get the amount funds transfer from E-pay to E-card.

The flow do not need to enter E-pay account password, the reasons are: a E-pay account only corresponding to a unique Ecard account, so all of the design is limited to transferring between E-pay accounts and their corresponding E-card accounts, E-pay should not be paid to the account of other people's E-card. The chance for the lawless people to get both the E-card and E-pay account information is small. Once the Ecard is reported loss, the operation can not be carried out, so safety is assured. Therefore, for convenience, enter password will not be required to.

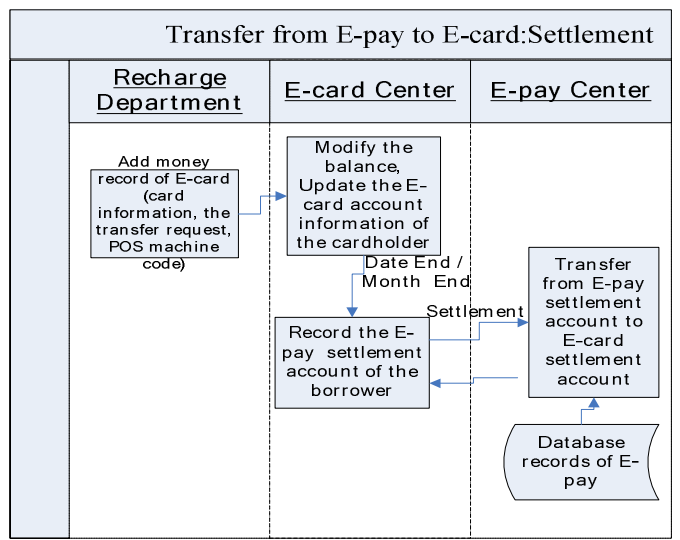

Figure 6. The settlement flow of transferring from E-pay to E-card

Its settlement deal flow as shown in Figure 6. Just like the settlement of transferring from the E-card to E-pay.

\section{B. Program 2}

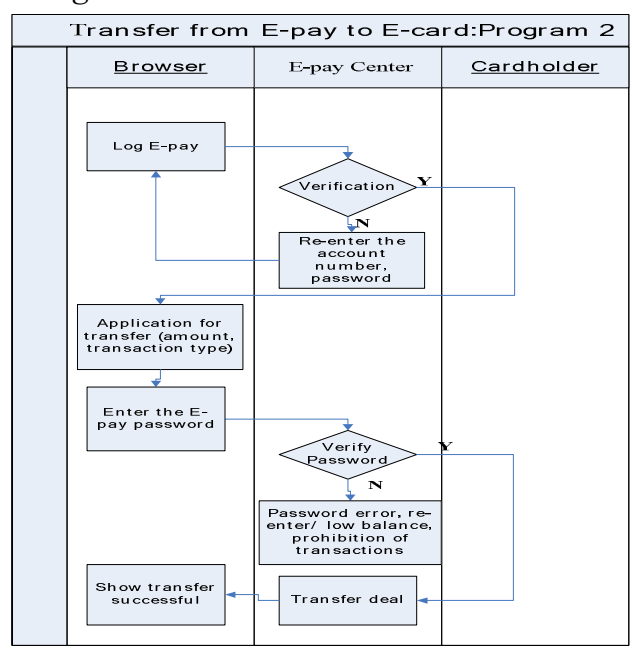

Figure 7. The flow of transferring from E-pay to E-card (Program 2)

The flow of transfer from E-pay to E-card (Program2) is shown in figure 7. Through the browser, user enters the E-pay payment page. Then enter the account number and password to $\log$ in the personal E-pay account. After the system verifies the legitimacy of account and password, User can submit online applications for transferring, including transfer amount and transaction type. If the transfer amount is greater than E-pay account balance, it shows the prohibition of transfer. After system returns the success of transfer, as long as the cardholder using the E-card for consumption, the system will automatically transfer the amount to the E-card. 
The flow of transferring from E-pay to E-card of Program 2 is shown in Figure 8.

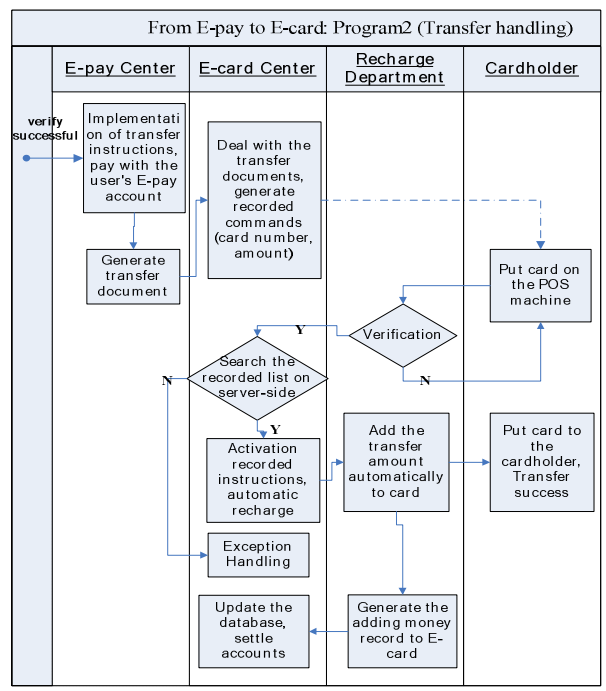

Figure 8. The transfer dealing flow from E-pay to E-card (Program 2)

When the user enter the password of E-pay payment, system will verify the password is correct or not, and confirm the transfer amount is not more than E-pay balance, and then the verification is successful.

Based on user's submitted transfer applications of the implementation of transfer orders, E-pay center deduct the amount from user's E-pay account. At the same time generate the transfer documents and send to the E-card center. The Ecard center deals with the transfer documents and generates recorded instructions. When cardholder use the E-card to consumer, the system verifies that the card can be used normally or not. at this time if the POS machine in online status, the system will automatically search in the E-card recorded list by server-side, if the card number exists, the POS machine automatically activate recorded instructions, the Ecard automatically increase the amount of transfer. At the same time, the POS machine to generate the record, sent to the ECard Center for updating database and the settlement. Its settlement flow is the same as program 1.

\section{CONCLUSION}

The proposing of E-pay payment provides solutions for the online application of E-card. We give a detail description for the flow of recharge, transfer and settle accounts based on the E-pay Payment Framework.

Based on the E-card in Campus, using the E-pay payment framework can make the campus payment activity more convenient. The E-card Center and E-pay Center are the manger Center of campus payment activity.

The users who have the E-card and E-pay account can make their payment in campus online. This conducive to the implementation of the School's electronic.

\section{REFERENCES}

[1] XU Caihong, "Study on-Line Payment System of Campus Eelctronic Commerce," Computer Knowledge and Technology, 2007(21):751752,785 .

[2] Hongfang Li, "Design of a High Safety Multipurpose Smart Card System in Campus," Computer and Modernization, 2005,2,78-80.

[3] YANG Wangming, "Based on Web Service Technique Research of Application Intergration of Third-party System in Carded-compus," Science Technology and Engineering, 2005,20,1522-1524 